\title{
Problems of Teaching and Learning English in Lorestan Province High Schools, Iran
}

\author{
Omid Tabatabaei \\ Department of English, Najafabad Branch, Islamic Azad University, Najafabad, Iran \\ Email: tabatabaeiomid@yahoo.com \\ Maryam Loni \\ Department of English, Najafabad Branch, Islamic Azad University, Najafabad, Iran \\ Email: maryamloni84@yahoo.com
}

\section{Doi:10.5901/mjss.2015.v6n2s1p47}

\begin{abstract}
Learning another language such as English is not a simple task. A lot of studies have been done to determine the problems of teaching and learning English. The present study was an attempt to investigate the problems of teaching and learning English in high schools of Khorramabad, Aligoodarz and Broujerd in Lorestan province, Iran. By investigating the relationship between the availability of educational facilities, and quality of learning, this study also tried to probe more problems by searching through learners and teachers' opinions. For this purpose, one standard Likert scale questionnaire and an interview were the main instruments of data collection. The questionnaire was given to 240 EFL learners (males \& females) at high schools who were randomly selected out of 10 high schools. In order to collect the required data, 10 English teachers and 30 students (males \& females) were interviewed as well. To analyze data, SPSS version 19 was used. The results of statistical analyses revealed that there was no significant relationship between the availability of educational facilities in Lorestan high schools and the quality of learning from EFL learners' point of view. The findings of interview indicated that the major problems were related to lack of target language use in the class, restricting the evaluation merely to midterm and final exams, classes being overcrowded, the absence of language laboratories and also the mere use of textbook ignoring any inclusion of supplementary materials such as CDs, movies and other instructional aids to create a more effective methodology. At the end of the study some solutions were suggested to overcome these problems.
\end{abstract}

Keywords: EFL; materials and syllabus; teaching methods; high schools; problems of teaching and learning English, Lorestan Province, Iran

\section{Introduction}

The history of Language teaching in Iran can be traced back to 1851 when the government has opened Dar-ol-Fonun as the first institution in Tehran (Tabatabaei \& Pourakbari, 2012). The emergence of English books in curriculum of schools came back to 1940. In 1971 students in middle and secondary schools have received English instructing. From 1971 to 1988, the authorities have determined to add English language course in all three grades of junior high school and four grades of secondary school. Later, they have decided to exclude English course from the first grade of junior high school curriculum.

From the emergence of language courses in Iran curriculum, the related practitioners in the field of teaching have got several problems in teaching them. They faced with some problems such as; the materials, proficient teachers, good facilities, lack of motivation in students to learn the language. Throughout the history of language teaching a lot of attempts have been made to omit these problems. They aimed to accelerate the process of language learning. In some cases they were successful but in other cases they weren't. These endeavors are also continuing. Despite these attempts, language learning like English learning in Irans' schools has not achieved its goal. This is because of various problems in the process of teaching. All of these can be good reasons to convince a researcher to investigate the current problems in English language learning in Iran's schools. 


\section{Literature Review}

\subsection{Studies related to Characteristics of a Good Language Learner, Teacher, and Syllabus}

Thompson (2008) explains characteristic of a good teacher. She enumerated some features which make a teacher, a good teacher. Thompson believes that good teachers have some features like patience and respect. She also adds more features like selecting proper plans and designing interesting tasks as other important characteristics of a good teacher. Teachers should also try to create a friendly atmosphere in the class in order to encourage learners to be involved in the learning process.

Ghasemi and Hashemi (2011) did an investigation. They investigated characteristics of a good teacher from students' point of view in terms of subject matter knowledge, pedagogical knowledge, and socio-affective skills. They have found that, reading and speaking proficiency are the most desirable characteristics of good teachers. Moreover, some of the participants in this study have determined listening and grammatical ability as the most important characteristic.

Lightbown and Spada (1997) have conducted an investigation to identify good characteristic of language learners. Their study has shown that a good language learner possesses a high intelligence, good academic skills and enjoys the process of learning. They also found that good learners tend to make mistakes. They are also good guesser and try to communicate. Beginning to learn in childhood, analyzing their own speech structure, enjoy grammar, and high self esteem are the other characteristics of good language learners which were identified by researchers.

In syllabus realm a lot of studies have been done (Trepanier 2008 \& Nunan 2006). Nunan (2006, p.5) contends that regarding the differences between a syllabus and curriculum development there are various viewpoints. He proposes two approaches to syllabus design, "a broad and narrow approach". In the first approach namely broad approach integration of content and tasks is considered but in the second approach, distinction of the syllabus and methodology is considered.

\subsection{Studies Related to the Teachers' Problems}

In a study Bahari (1989) examined middle and high school teachers in the urban schools of Shiraz in Fars province, Iran, who had two jobs. He identified several teachers who had second jobs along with their first jobs. Finally, the study has pinpointed some of the reasons that made teachers to have a second job such as; low range of salaries and low social status.

In another study Coston (1977) examined the in-service training of English teachers in the secondary schools in Iran. He tried to identify the problems of teaching and learning English. His study has shown that most of the problems rooted from teachers. He believes that teachers are mostly demotivated because of the lack of status. Therefore, they ignore communicative competence as an aspect of language learning and this leads to lack of communicative competence in most of high school graduates.

Gharabaghi (1991) conducted an investigation to examine the most important element in the classroom, namely teachers. In order to do this investigation, Gharabaghi studied the plan of the Ministry of Education designed to decrease lack of teachers' problem in Iran. The ultimate result of Gharabaghi's investigation might be a help to train good teachers.

\subsection{Studies Related to Methods}

For the sake of language teaching several methods have been devised. For example, GTM was the most popular method for years. After that different methods such as direct method, ALM, silent way,... were developed based upon different views of language learning and linguistics. In Iran GTM is still one of the methods which most of the teachers enjoy it. Therefore, some studies have tried to investigate about this method (Saadat 1995 \& Ghorbani 2009).

Saadat (1995) believes that various methods were employed from time to time. Iranian teachers are not exceptional and they have employed different methods and instructions to teach language in different periods. Saadat stated that GTM was used in English classes in Iran in one time and in another time ALM was used.

In one study Ghorbani (2009) found that before the 1990s, high school English teachers have employed GTM in their classes. Therefore, their classes were confined to reading comprehension and boosting up the learner's grammar knowledge. He also noticed that books were affected by this method of language teaching.

Rahimi (1996) conducted an investigation in order to specify problems of teaching and learning in the high schools of Iran. He finally pointed out that ALM was not satisfying in most of the English schools in Iran. This study has also 
revealed that:

a) The context of textbooks is not appropriate for the students' mental ability b) the textbooks do not use jokes and poems, etc. c) the teachers are not pleased with their incomes.

Because of utmost value of English learning, particularly in Iran, this study tries to explore some problems of language teaching and learning in one of the province of Iran, i.e. Lorestan. A lot of studies have shown that despite training of learners several years and employing different methods and techniques to achieve a desirable result, they cannot handle a simple conversation (Saadat, 1995). In fact they couldn't develop their communicative competence in the second language. This seems to be a convincing reason to lead a researcher to investigate in this area because the presence of problems can be felt and a thorough investigation is prerequisite.

\subsection{Objectives of the Study}

Although learning English is an important subject matter in Iran schools and a lot of attempts have been made to teach this subject matter, it has not successfully been achieved. Therefore, the aim of present study is to investigate the problems of teaching and learning EFL in high schools of Lorestan Province, Iran. Therefore, to alleviate these problems, the current investigation seeks to answer the following questions.

\subsection{Research Questions}

An attempt has been made in this study to find appropriate answers for the following questions:

1) Is there any significant relationship between the availability of educational facilities in Lorestan high schools and the quality of learning from EFL learners' point of view?

2) What are the most important problems of teaching and Learning English in Lorestan Province High Schools from EFL teachers' and learners' point of view?

\subsection{Research Hypotheses}

1) There is no significant relationship between the availability of educational facilities in Lorestan high schools and the quality of learning from EFL learners' point of view.

\section{Methodology}

\subsection{Participants}

In order to conduct this study, 240 participants were employed. They were males and females and their ages range from 15 to 19. They were randomly selected out of ten high schools in Khorramabad, Aligoodarz and Broujerd. The participants were first, second, and third grades in high school. In order to interview, 10 English teachers who were composed of males and females and 30 students (males and females) were used. Their ages range was between 30 and 45.

\subsection{Instruments}

In order to gather data, a questionnaire and an interview were used. The questionnaire was adopted from Pourakbari (2012). To ascertain that this questionnaire fits the intended purposes, some slight modifications were made to enhance its suitability. Then the final version was composed of 21 items. The validity of the questionnaires was confirmed by three experienced professors of the Department of English at Islamic Azad University - Njafabad Branch.

To check the reliability of the questionnaire, a pilot study was conducted. To do the pilot study 30 high school students who were males and females were chosen. The numbers of participants were equal in terms of gender. The reliability of the items were estimated by Cronbach's alpha was \%75. The items in the questionnaire were related to learning quality and educational facility. In addition, a face to face semi-structured interview was conducted to gather information from 30 high school students and 10 English teachers. 


\subsection{Procedures}

\subsubsection{Quantitative Stage}

To prevent any probable misunderstanding, the questionnaire was translated into participants' native language. The pilot study was conducted on 30 high school students who were males and females. To conduct the main study, the questionnaire was delivered to 240 high school students in order to complete it. Because of the research questions the descriptive method in the form of survey was used.

\subsubsection{Qualitative Stage}

In this study ten English teachers ( 5 males \& 5 females) and 30 students ( 15 males \& 15 females) were interviewed. The purpose of doing interview was to know how they think about the topic of the study. Each of them was interviewed about half an hour. Their speeches were tape recorded and transcribed.

\subsection{Data Analysis}

After completion of the questionnaires, the raw data were ready to be analyzed. The students' questionnaire included 21 questions in two categories. To determine the relationships between these two variables the correlation of data was analyzed. All the statistical analyses were conducted by SPSS 19. In addition, the data which were gathered through interview were analyzed and percentage of data was calculated.

\section{Results}

\subsection{Investigating the Students' Questionnaire}

\subsubsection{The First Research Question}

The completed questionnaires were gathered and analyzed to answer the research question. Table 4.1 illustrates the descriptive statistics for different categories of the questionnaire-that is, learning quality, and educational facilities- and Figure 4.2 graphically illustrates the means.

Table 4.1. Descriptive Statistics for the Students' Questionnaire

\begin{tabular}{|c|c|c|c|}
\hline \hline Group & $\mathrm{N}$ & Mean & SD \\
\hline Learning Quality & 240 & 3.4271 & .95195 \\
Educational Facilities & 240 & 3.1736 & .27100 \\
\hline
\end{tabular}

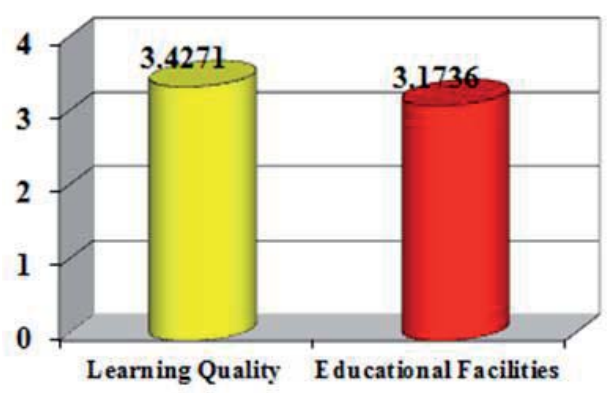

Figure 4.2. Graphical representation of the means for the categories of the students' questionnaire

In order to determine the significance of correlations between the categories, the correlations were calculated. Table 4.3 indicates the results of the correlational analyses. 
Table 4.3. The Results of the Correlational Analyses for the Students' Questionnaire

\begin{tabular}{llll}
\hline \hline & & Educational Facilities & Learning Quality \\
\hline Educational & Pearson & 1 & -.012 \\
Facilities & Correlation & & \\
& Sig. (2 tailed) & & .849 \\
& $\mathrm{~N}$ & .240 & .240 \\
\hline Learning Quality & Pearson & -.012 & 1 \\
& Correlation & & \\
& Sig. (2 tailed) & .849 & 240 \\
\hline
\end{tabular}

${ }^{*}$ Correlation is significant at the 0.05 level (2-tailed).

The data in Table 4.3, shows that there is no significant relationship between the availability of educational facilities of high school and the learning quality of the learners $(r=.849, p=-.012)$. Therefore, the hypothesis stating that, "There is no significant relationship between the availability of educational facilities in Lorestan high schools and the quality of learning from EFL learners' point of view" is confirmed, and it seems that the educational facilities have no direct effect on students learning quality.

\subsection{The Results of Interviews}

To answer the second research question, it was necessary to collect more data; thus, an interview was held with both the teachers and the students. This section gives the results of the analyses of the interviews.

\subsubsection{Findings from Interviews of High school Students}

Based on students' responses $96.6 \%$ of parents care about their learning of English however, about $73 \%$ of the students complain about their parents' lack of knowledge in English. They asserted that their parents do not have enough skill in English to help them. As table 4.4 shows, $83.3 \%$ of the students also were not satisfied with their teachers. They were dissatisfied with their methods of teaching. They said that their teachers mostly employ traditional methods in the classes and they neglect correct pronunciation of the students. They also stated that classes are more teacher-centered.

Based on $70 \%$ of students, their mother tongue is the medium of instruction in language classes which can be regarded as an important problem. Another problem of language teachers which was pinpointed by $60 \%$ of students was the lack of plan in their courses based on students' needs and interests. They thought that teachers never want students to choose topic for free discussion and evaluations are merely restricted to midterm and final exams.

The results presented in table 4.4 , indicates that $86.6 \%$ of student believe that physical conditions of the classrooms are poor and their classrooms are overcrowded and $63.3 \%$ of them expressed their dissatisfaction with the unavailability of supplementary material and equipment especially laboratories. They expressed because of these problems, they attend to language institutes. They believe that in language institutes the conditions are better than high schools in terms of the books and equipments. About $80 \%$ of students state that they need more time for oral skills and to solve their English problems. According to the results, most of the students (93.3\%) declared that 3 hours a week is not enough for teaching English in high schools.

Table 4.4. Findings from Interviews of High school Students

\begin{tabular}{|l|c|c|c|c|}
\hline Interview Questions & $\begin{array}{c}\text { Negative } \\
\text { opinions }\end{array}$ & $\begin{array}{c}\text { positive } \\
\text { opinions }\end{array}$ & Number of students & Number of students \\
\hline Parents care about learning English & $\% 3.4$ & $\% 96.6$ & 1 & 29 \\
Parent's help & $\% 73$ & $\% 27$ & 22 & 8 \\
Teachers method & $\% 83.3$ & $\% 16.6$ & 25 & 5 \\
The use of English language & $\% 70$ & $\% 30$ & 21 & 9 \\
Teachers use lesson plan & $\% 60$ & $\% 40$ & 18 & 4 \\
Physical conditions of the class & $\% 86.6$ & $\% 13.4$ & 26 & 11 \\
Existence of library & $\% 63.3$ & $\% 36.7$ & 19 & 6 \\
Enough time for oral exercise & $\% 80$ & $\% 20$ & 24 & 2 \\
Enough time for teaching English & $\% 93.3$ & $\% 6.7$ & 28 & 30 \\
Total numbers & $\% 100$ & $\% 100$ & 30 & 4 \\
\hline
\end{tabular}




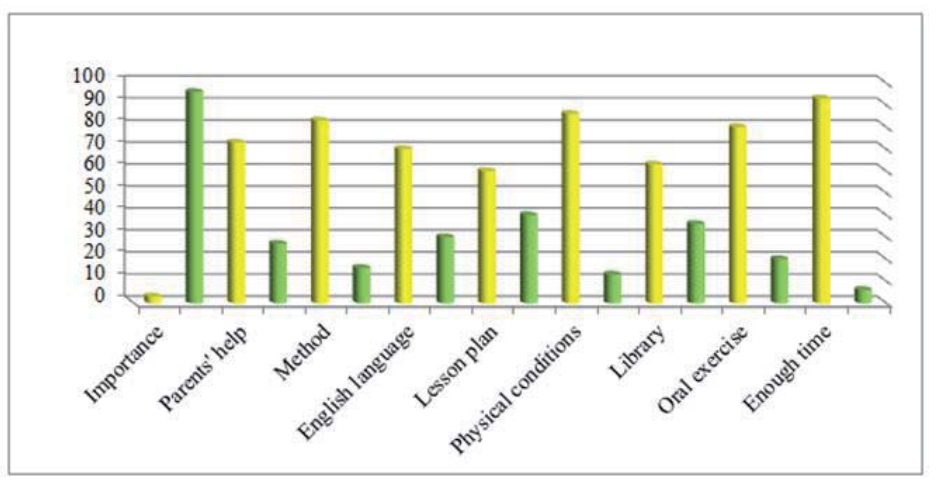

Figure 4.5. Graphical representation of the students' interview

\subsubsection{Findings from Interviews of EFL High school Teachers}

Based on teachers' responses to the interview, $70 \%$ of them believe that the schools are not equipped with enough equipment to create a suitable condition for teaching English. They also had complaint about the numbers of students and they mentioned that overcrowded classes make stressful conditions for them to work and this can reduce the efficacy of language teaching in classes. The percentages displayed in table 4.6 clearly show that $60 \%$ of the English teachers believed that language learning needs oral exercises and some disturbing factors such as: large numbers of students, shortage of time, and lack of enough facilities hinder this to happen. $60 \%$ of the teachers are interested in teaching and they like their jobs, but they believe that assiduous and proficient teacher are equal with poor teachers.

Table 4.6 represents surprising results $100 \%$ of the English teachers claim that their salary is not sufficient as well. As is clear from the data displayed in table 4.6 , about $70 \%$ of them believe that teachers' manual is not available in schools but it is useful in their teaching procedures. It is very interesting that according to the data displayed in table 4.6, $80 \%$ of teachers state that they try to motivate learners and to accelerate the process of learning.

Table 4.6. Findings from Interviews of High school Teachers

\begin{tabular}{|l|c|c|c|c|}
\hline Interview Questions & $\begin{array}{c}\text { Negative } \\
\text { opinions }\end{array}$ & $\begin{array}{c}\text { positive } \\
\text { opinions }\end{array}$ & Number of teachers & Number of teachers \\
\hline Educational equipments & $\% 70$ & $\% 30$ & 7 & 3 \\
Paying attention to 4 skills & $\% 60$ & $\% 40$ & 6 & 4 \\
Job's satisfaction & $\% 40$ & $\% 60$ & 4 & 6 \\
Teachers salary & $\% 100$ & $\% 0$ & 10 & 0 \\
Teachers manual & $\% 70$ & $\% 30$ & 7 & 3 \\
Teachers creativity & $\% 20$ & $\% 80$ & 2 & 8 \\
Total numbers & $\% 100$ & $\% 100$ & 10 & 10 \\
\hline
\end{tabular}

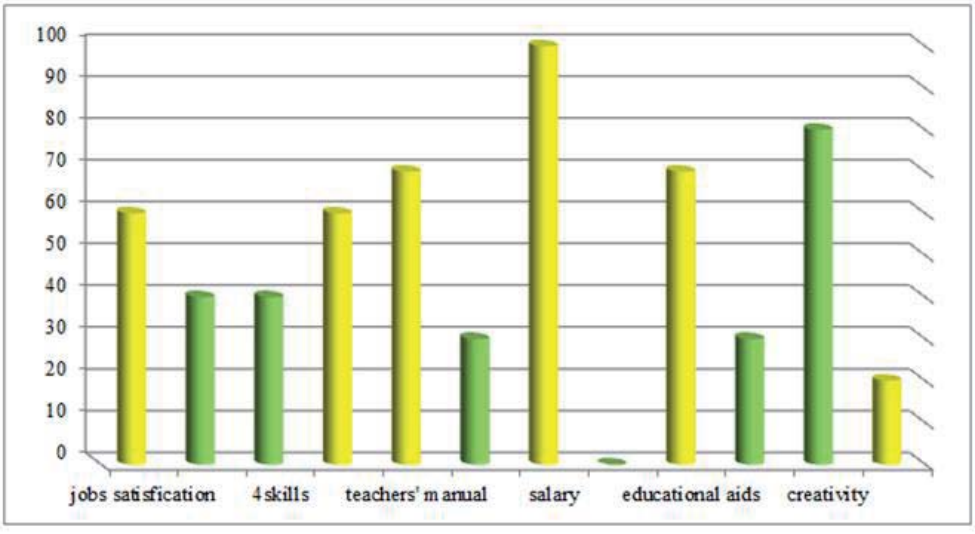

Figure 4.7. Graphical representation for the teachers' interview 


\section{Discussion}

The purpose of the present study was to pinpoint the problems of teaching and learning English in Lorestan high schools. In fact, the aim was to find some problems of teaching and learning English in order to obviate them and to facilitate the process of teaching and learning. As mentioned before, this study focused on two questions. The first research question was whether there is any significant relationship between the availability of educational facilities in Lorestan high schools and the quality of learning from EFL learners' points of view. The hypothesis also indicated that there was no significant relationship between the availability of the educational facilities in Lorestan high schools and the quality of learning from EFL learners' points of view. The statistical results revealed that there was no significant relationship between the educational facilities of the high schools and the learning quality of the learners $(r=-.012, p=.849)$.

However, students' responses to the interview showed that $63 \%$ of the students were dissatisfied about the unavailability of supplementary materials and equipment, particularly libraries and laboratories. They believed that libraries can provide different sources and books in the related courses and they can use them. It can be understood that the only source for learning English is not students' high schools. They are mostly exposed to these facilities in the institutes. They attend to institutes, and they are introduced supplementary books, CDs, and videocassettes to improve their knowledge of English.

The second research question sought the most important problems of teaching and learning English in Lorestan high schools. To answer the second research question an interview was conducted. Finally, this study indicated some additional problems such as the lack of target language use in the class, restricting the evaluation to midterm and final exams, classes being overcrowded, the absence of well-equipped computer sites and language laboratories and also the mere use of textbook without taking advantage of supplementary educational aids.

The findings of this study are in line with the findings of Tabatabaei and Pourakbari's (2012) and also Rahimi's (1996) study. Based on students' responses to the interview 73\% of them asserted that their parents do not have enough knowledge in English and they cannot help them in their English problems. Therefore, by considering students' responses, it can be concluded that parents' education plays an important role in English learning of students.

Another problem which was identified by $83 \%$ of the students was that the English teachers do not use the educational aids in the classroom. It may be as a result of two reasons. The first one is that there is not enough facilities at schools and teachers cannot provide educational aids by their own. The other reason may be due to insufficient time which was allocated to English classes. Teachers cannot use educational facilities in the classroom because they should cover the material of the books per se as a result of dearth of time.

The other problem which was introduced by $83 \%$ of the students was the restriction of students' evaluation to midterm and final exams. Teachers can be more flexible in evaluation. They can enhance the reliability of their evaluations by adding practical projects for evaluation. They should not limit their evaluation to mere administration of midterm and final exams because some of the students cannot show their abilities in these exams.

The other problem which was identified through $86 \%$ of the students again was overcrowded classes. Teaching in overcrowded classes is difficult because there is not enough time to allocate every learner and all of them cannot practice oral exercises. Thus, the teacher cannot implement communicative method in the class as a result of populated class which hinders teachers to spend time on each student.

Different problems were identified by teachers' responses to the interview too. One of them was the teachers' dissatisfaction with their incomes. It seems that those teachers who are involved in two jobs as a result of insufficient income do not give value to the quality of teaching because they have got their own problems in their life. The findings of this study can be a support to the study which was done by Bahari (1989) in the province of Fars.

The results of the current study revealed that about $70 \%$ of teachers use their first language to communicate in the classroom and this can reduce students' exposure to the target language and ultimately does not lead to good language learning. This problem may be rooted in the teachers' insufficient capabilities in the target language. They are not enough proficient to be able to use target language in the classroom and this problem may be as a result of inaccurate choose of ministry of education in employing teachers.

Another problem which may be caused as a result of teachers' low level of proficiencies is the use of GTM in English classes instead of communicative competence. They are not enough skillful in the target language to teach language communicatively. Therefore they are forced to use GTM in the classroom. The purpose of GTM is not to teach language in a communicative way. However, the purpose of language learners is to learn language in order to be able communicative effectively.

It seems that GTM doesn't empower learners to communicate effectively because of some of its wrong procedures and the implementation of the GTM by teachers in class can be regarded as an inappropriate method for teaching all 
aspects of language which hinders students' language learning. The results of this study confirm the findings of Mahmoodi (1990) and Musavi (2001). They also believed that teachers in high schools classes use outdated methods and their focus is mostly on grammar instead of reading and communicative tasks. Also, the current study results are in line with Coston (1977) who has carried out it on in-service training of teachers of English in the secondary schools in Iran.

The other problem can be attributed to the lack of control from educational system on teachers' activities in the classes. Teachers neglect correct pronunciation of students and they don't employ proper method and technique in the classroom. They don't involve students in free discussion by asking them to choose a topic. Teachers follow a traditional model of instruction in their classes. They don't use a lesson plan and there is no interaction between teachers and students. Actually they conduct their classes as teacher-centered classes. They play the major role in the class and they considered student as passive listener in the class.

In relation with these findings Noora (2008) also found that the culture of teaching in Iran is teacher centered. In order to learn vocabulary it was found that they try to learn vocabulary by translating texts into Persian and memorize some vocabularies. They also try to learn new words by using a long list of words with their Persian equivalent without contextualization. It is clear that these two techniques are popular in GTM method and it was found that they are not effective techniques to improve vocabulary knowledge productively. Nunan (1999) also highlighted the inefficiency of traditional techniques such as translation, and explanation in developing vocabulary knowledge since they cannot help learners use language productively.

\section{Conclusion and Implication}

The present study was set up to investigate various problems regarding teaching and learning English as a foreign language in high schools of Lorestan province. After collecting and analyzing the data, it was found that there is no significant relationship between two variables of research question namely, educational facilities and quality of learning. The other instrument which was used in this study to collect data was an interview which revealed some problems regarding teachers, learners, syllabus design, methodology and educational facilities.

In light of the results of the present study, some pedagogical implications can be suggested to eradicate the problems of teaching and learning. One of the significant implications of the study is that, the Ministry of education needs to provide schools with proper educational aids and libraries. The other implication is related to policy makers and it suggests that policy makers should increase teachers' salaries in order to encourage them to work more effectively. It is necessary for them to be cautious enough during employing teachers. They need to employ the most qualified one as a teacher.

The Ministry of Education should try to enhance the class time and to reduce the number of students in overcrowded classes. The last implication of this study targeted teachers. Teachers should implement appropriated methods and techniques in the classroom to motivate learners. They need to create an encouraging atmosphere in the classroom and they should try to meet individual needs. They should use English language as a medium of instruction in the classroom.

\section{References}

Bahari, M. (1989). Moonlighting among Iranian teachers. Arizona State University Bailey, K. M., and L. Savage eds. (1994). New ways in teaching speaking. Alexandria, VA: TESOL.

Coston, J. (1977). Approaches to the in-service training of teachers of English in secondary school. Proceedings of the seventh annual conference of the Association of professors of English Iran (A.P.E.I). (PP. 206-218).

Gharabaghi, S. (1991). Foreign Language Teacher Training in Iran. Austin: The University of Texas.

Ghasemi, B., \& Hashemi, M. (2011). The study of the characteristics of successful English language teachers from the view point of the English language students of Islamic Azad University, Hamedan Branch. Procedia-Social and Behavioral Sciences, 28, $411-415$.

Ghorbani, M. R. (2009). ELT in Iranian high schools in Iran, Malaysia and Japan: Reflections on how tests influence use of prescribed textbooks. Reflections on English Language Teaching, 8(2), 131-139.

Lightbown, P.M., \& Spada, N. (1997). How Languages are Learned, (7th Impression). Oxford: Oxford University Press.

Mahmoodi, G. (1990). Analysis of English language teaching problems and failure in the Educational System. Roshd Language Teaching Journal, 22, 13-19.

Musawi, Z. (2001). An Overview of the TEFL Situation in Various Countries http://www. asahi- net.or.jp/ykt/overview4.html

Noora, A. (2008). Iranian undergraduate non-English majors' language learning preferences. GEMA Online Journal of Language Studies, 8(2), 33-44. 
Nunan, D. (1999). Second Language Learning and Teaching. New York: Newbery House.

Nunan, D. (2006). Syllabus design. (P.5) Language teaching. Oxford university press. Tehran: Jungle Publication.

Rahimi, M. (1996). The study of English Language Instruction at the Secondary Schools of the Isfahan Province. Unpublished M.A. Thesis, Shiraz University, Shiraz.

Saadat, M. (1995). An Investigation into the Problems of Teaching and Learning English in the Guidance and High Schools of Fars Province. Unpublished M.A. Thesis, Shiraz University, Shiraz.

Tabatabaei, O, \& Pourakbari, A. A. (2012). An investigation into the problems of teaching and learning English in the Isfahan Province high schools, Iran. Journal of Language Teaching and Research, 3(1), 102-111.

Thompson, S. (2008). Defining a good teacher simply. Modern English Teacher, 17(1), 5-14.

Trepanier, L. (2008). What makes a good syllabus? ISI's American Studies Center. Retrieved: November 29, 2011, http//Faculty.isi.org/ blog/post/view/id/32. 